\title{
Compra de voto en Colombia: ¿cómo viste el fantasma y cuáles son sus implicaciones?
}

\section{Vote buying in Colombia: How does the ghost dress and what are its implications?}

\author{
Luis González Tule (D) \\ Universidad del Norte, Colombia \\ ltule@uninorte.edu.co
}

\begin{abstract}
Resumen
A pesar de que la compra de votos es una práctica común en las elecciones colombianas, existe poco desarrollo investigativo que documente cómo operan las redes y cuáles son sus efectos en las instituciones democráticas y en el bienestar de la población. Este trabajo describe el funcionamiento de una red dedicada a la compra de voto a partir de un estudio de caso de gran relevancia ocurrido en Colombia, y expone algunas de las implicaciones de esta práctica. Se sostiene que la compra del voto, además de constituir los delitos de corrupción al sufragante y financiamiento ilegal de las campañas, impacta negativamente en dos pilares de la democracia moderna: la representación y las elecciones; profundizando las desigualdades sociales. El caso evidencia que la compra de votos afecta en especial a los más pobres, siendo estos, paradójicamente, los más propensos a participar en la transacción.
\end{abstract}

Palabras clave: compra de voto, Estrategia de movilización electoral, Corrupción, Colombia.

\section{Summary}

Although vote buying is a common practice in Colombian elections, there is little research that explores how networks operate and what their effects are on democratic institutions and the well-being of the population. This paper describes the operation of a vote buying network, based on a highly relevant case study occurred in Colombia, and discuss some of the implications of this practice. I argue that vote buying not only constitutes two electoral crimes, but impacts on political representation, elections, and deepens social inequalities. The case shows that vote buying affects especially the poorest, they are, paradoxically, the most likely to participate in a transaction.

Keywords: Vote buying, Strategy of electoral mobilization, Corruption, Colombia.

Articulo: Recibido el 28 de septiembre de 2020 y aprobado el 27 de octubre de 2020

\section{Cómo citar este artículo:}

González Tule, LA. (2020). Compra de voto en Colombia: ¿cómo viste el fantasma y cuáles son sus implicaciones? Reflexión política 22(46), pp. 44-57. doi: https://doi.org/10.29375/01240781.3992

\section{Introducción}

La compra de voto es un fenómeno extendido en democracias en desarrollo y ampliamente documentado en la academia desde distintas perspectivas metodológicas y analíticas. La variedad de aproximaciones ha enriquecido nuestro conocimiento sobre un fenómeno de vital importancia en países de ingreso medio y bajo. Algunas preocupaciones que destacan dentro de la literatura tienen que ver con la eficacia de la compra de voto como estrategia de movilización electoral (Vicente, 2014; Greene, 2016), con el target 
(público) al que va dirigido el beneficio, diferenciando entre votantes leales o indecisos (Calvo y Murillo, 2004; Stokes, 2005; Díaz Cayeros et. al., 2016), con los factores que favorecen esa práctica, al presentarse con mayor intensidad y frecuencia en localidades pobres (Sandholt y Justesen, 2013) y con los efectos que produce en distintos componentes del régimen (Stokes, 2005; Stokes, 2007).

Sobre esta última línea, todos los autores coinciden en que la compra de voto daña la democracia porque afecta la rendición de cuentas y la responsabilidad de quienes ocupan un cargo de elección, limita la capacidad ciudadana para elegir libremente a los gobernantes y representantes, mina la calidad de la política pública que emana de los políticos que ganaron comprando votos, invierte el sentido de las elecciones como instrumentos de toma de decisiones políticas, agudiza las desigualdades sociales, altera los resultados electorales, promueve incentivos erróneos a los candidatos elegidos y genera un gasto excesivo cuyo origen de los recursos es ilegal (Stokes, 2005; 2007; Schaffer, 2007a; 2007b).

En contraste con la atención que ha recibido este problema en otras latitudes, en Colombia continúa siendo un tema pendiente en la agenda investigativa a pesar de ser una práctica recurrente en los procesos electorales ${ }^{1}$. A la poca atención se añade el predominio de análisis cuantitativos en la producción más reciente, en donde se prioriza el uso de datos sociodemográficos y de encuestas por encima de otro tipo de análisis y formas de recolección de información (ver Fergusson et. al., 2017; y Rueda, 2017). La ausencia de investigaciones sustentadas en entrevistas que recopilen información de primera mano, en este caso de los involucrados en la compraventa del voto, plantea la necesidad de continuar estudiando el fenómeno para conocer cómo operan las redes, cuándo y por qué surgen, y cuáles son las consecuencias de esta práctica.

El presente trabajo apunta en esa dirección. Se pretende describir el funcionamiento de una organización dedicada a la compra de votos y reflexionar sobre sus implicaciones en el régimen democrático. Para ello se analiza la red que encabezó la candidata al Senado Aída Merlano, en la ciudad de Barranquilla, durante las elecciones generales de 2018. Se argumenta que la compra del voto, además de constituir los delitos de corrupción al sufragante y financiamiento ilegal de las campañas, impacta negativamente en dos pilares de la democracia moderna: la representación y las elecciones; profundizando las desigualdades sociales. Para dar forma al entramado, se realizaron entrevistas a informantes clave, celebradas en la ciudad de Barranquilla.

El trabajo está dividido en cuatro partes. La primera ofrece una definición operativa de la compra de voto a fin establecer los criterios de este concepto y dar claridad para distinguirlo de otros modos de distribución de beneficios particulares y otras estrategias de movilización electoral. En esta misma sección se lleva a cabo el debate en torno a las implicaciones políticas, sociales y jurídicas de la compra de votos. La segunda presenta la estrategia de recolección de datos y fuentes de información. Una tercera parte está dedicada al análisis del caso, se inicia con un esbozo del contexto político-institucional en el que se celebraron las elecciones generales de 2018 en Colombia, así como la detención y juicio de Aída Merlano. Enseguida tiene lugar el análisis descriptivo en donde se pondrá especial atención al modus operandi de la red, su organización, recursos, integrantes y funciones. La última parte concluye con el análisis de las implicaciones de la compra de voto.

${ }^{1}$ Esta desatención no se extiende al estudio del clientelismo político, otra de las formas de distribución de beneficios particulares. Por citar algunos de los trabajos más relevantes, destacan las investigaciones de Guillén (2008), quien analiza los esquemas de dominio durante el Frente Nacional (FN) en el que los partidos Liberal y Conservador aprovecharon las relaciones de lealtad heredadas de la encomienda y la hacienda para consolidar la dependencia de las clases medias y bajas hacia el poder político. Leal y Dávila (2010), por su parte, abordan el fenómeno en la segunda mitad del siglo XX, tanto a nivel nacional como municipal, y sostienen que tras quedar agotada la estructura bipartidista, el clientelismo pasó a ser el principal sostén de la actividad política en el ámbito local. En la costa Caribe y a través de estudios de caso, Díaz (1986) esquematiza el entramado en el departamento de Sucre mostrando cómo las élites locales aprovecharon la fragmentación política con la llegada del Pacto de 1957 para consolidar sus redes clientelares con los sectores más marginales de la población; Ocampo (2014) muestra que en el departamento de Córdoba las relaciones interpersonales y jefaturas locales y regionales, insertas en los partidos, son la clave en la relación entre el poder local y el Estado central; por último, González et al. (2019) describen la manera en que se organizan las redes clientelares en el distrito de Barranquilla, evidenciando que se trata de estructuras complejas, verticales, con labores bien establecidas y que para llevar a cabo sus objetivos se apoyan en una amplia red de intermediarios. 


\section{La compra de voto: concepto y sus implicaciones}

\section{Delimitación conceptual de la compra de voto}

La compra de voto es un concepto de uso común y una práctica recurrente, sobre todo en democracias en desarrollo. A pesar de las múltiples referencias, en la literatura especializada la variedad de atributos que adopta el concepto es muy amplia, además de inconsistente. Si bien existe consenso en que es una práctica ilegal (Schaffer y Schedler, 2007; Nichter, 2014) e ilegitima en las democracias contemporáneas (Hagene, 2015), ${ }^{2}$ la connotación del concepto y su operacionalización pueden llegar a tener diferencias decisivas que distorsionan los hallazgos y dificultan las comparaciones (Nichter, 2014). Por ejemplo, algunos académicos han empleado el concepto para referirse a fenómenos tan disímiles como el traslado de electores de un distrito a otro para acudir a votar (Hidalgo y Nichter, 2016) -maniobra mejor conocida como trashumancia-, o el intercambio de transferencias o beneficios particulares por el voto (Fergusson, et al., 2017). Esta "falta de claridad conceptual" (Nichter 2014, p. 315) no hace más que limitar la acumulación de conocimiento descriptivo y del explicativo en el terreno empírico.

$\mathrm{Si}$ se pretende ampliar el conocimiento empírico, es necesario que los conceptos "tengan un significado perceptivo", es decir, que se valgan de la "observación" (Sartori, 2002, p. 37). Por ello, siguiendo el planteamiento de Nichter (2014), en esta sección se elabora una definición clara y explícita de la compra de voto. Asimismo, se delimita cada uno de los atributos que componen este fenómeno, a fin de que el significado corresponda con lo observado y de aportar precisión conceptual al debate académico. Dicho esto, se entiende por compra de voto la distribución contingente de beneficios particulares otorgados a un individuo o grupo de personas a cambio de su voto en periodos electorales. ${ }^{3}$

El primer elemento para destacar de la definición tiene que ver con la naturaleza de los bienes. Los beneficios particulares son aquellos bienes, servicios y dinero (Nichter, 2014) que las personas reciben en contraprestación al voto. La compra de voto no se restringe al dinero que se entrega en efectivo al elector, sino que incluye una amplia diversidad de bienes como mercado, comida, bebida, tejas, cisternas, cemento, medicinas, equipamiento deportivo, electrodomésticos, muebles, ropa, entre otros. A su vez, se incluyen una variedad de servicios como pavimentación, atención médica, suministro de energía eléctrica o agua potable, servicio de telefonía o internet, entre otros. Por el contrario, el ofrecimiento de empleo u otorgamiento de subvenciones y programas sociales no forman parte de la compra de voto.

$\mathrm{El}$ siguiente atributo es su alcance (scope). De igual forma que otros modos de distribución política, la compra de voto otorga beneficios particularistas dirigidos a un individuo o pequeño grupo de personas que forman parte del intercambio (Schaffer 2007a). Esto en contraposición a las asignaciones programáticas que contemplan una distribución universal o enfocada a grupos específicos de la población con base en criterios bien definidos (Stokes et al., 2013).

Otra característica de la definición es la temporalidad, pues tiene lugar solo en periodos electorales (Schaffer, 2007a; Nichter, 2014; Hagene, 2015). Por tanto, el beneficio puede ser entregado antes del día de las elecciones, durante la jornada electoral (Lehoucq, 2007), o en ambos momentos cuando se da un adelanto y se completa el total luego de ejercerse el voto-. Así, al ser una transacción única basada en el interés, en la obtención de ganancias, no se crea un vínculo duradero entre el político o partido político y el elector. Esta característica permite diferenciar la compra de voto de otros conceptos como el clientelismo político, el cual no solo tiene lugar en periodos electorales, sino que es de carácter permanente $\mathrm{y}$, puesto que resuelve problemas de la gente y distribuye recursos de manera personalizada (Auyero, 2012), engloba símbolos y teje una relación de confianza, lealtad y mutua reciprocidad; todas éstas, propiedades ausentes en la compra de voto.

El último atributo de la definición es que la entrega del beneficio es contingente, es

${ }^{2}$ Cabe señalar que, más allá del plano formal u objetivo, la compra de voto envuelve una serie de "barreras subjetivas", a través de las cuales los participantes -el vendedor y el comprador- pueden asignar "diferentes significados dependiendo el contexto" (Schaffer y Schedler, 2007, p. 5). Esto explica por qué en casos como el de Barranquilla la práctica continúa siendo aceptada y legitimada por los actores -tanto por el político como por el elector- a pesar de ser reconocido su carácter ilegal (Informante 1).

${ }^{3}$ Esta definición recoge algunos criterios propuestos por Nichter (2008; 2014), Lehoucq (2007); Schaffer y Schedler (2007); y Kitschelt y Wilkinson (2007). 
decir, condicionada al apoyo electoral (Kitschelt y Wilkinson, 2007). Dado que el acto de compraventa del voto es ilegal y se encuentra fuera de los márgenes del mercado "normal de consumo" -en donde las partes pueden apelar a una instancia judicial-, prevalece la incertidumbre sobre el cumplimiento del elector (Schaffer y Schedler, 2007, p. 7). La falta de certeza obliga al comprador a contar con mecanismos de vigilancia, monitoreo y/o coerción para asegurar que el vendedor cumpla con su parte del acuerdo que es depositar el voto (Stokes, 2005; Kitschelt \& Wilkinson, 2007). Contrario a esta práctica, nuevamente, son las distribuciones a través de políticas programáticas en las que los beneficios son dirigidos a grupos de la sociedad que no necesariamente votaron por el candidato. En este segundo escenario, el intercambio político es "indirecto y no contingente", sin monitoreo ni sanción a los electores (Kitschelt y Wilkinson, 2007, p. 10).

La delimitación conceptual aquí planteada permite diferenciar analítica y operativamente la compra de voto de otras estrategias de movilización electoral. Se puede distinguir de la compra de abstención (abstention buying), también conocida como compra negativa del voto (negative vote buying) ${ }^{4}$, de la compra de participación (turnout buying) ${ }^{5}$ y de la compra de desmovilización (nonvoter buying $)^{6}$. En el mismo sentido, es posible distinguir el concepto de otros modos de distribución de beneficios particulares como el clientelismo político $^{7}$, el patronazgo ${ }^{8}$, la política pork barrel ${ }^{9}$; y la compra de voto no vinculante (non-binding vote buying $)^{10}$.

\section{Debate en torno a las implicaciones de la compra de votos}

La literatura politológica coincide en afirmar que la compra del voto afecta la democracia al violar varios de sus principios y al socavar el funcionamiento de las instituciones politicas
(Schaffer, 2007a; 2007b; Stokes, 2007). La democracia, desde una concepción mínima, es un régimen caracterizado por una serie de prácticas, procesos y reglas para tomar decisiones colectivas (Bobbio, 1986; Tilly, 2007). Las normas establecen quiénes son los individuos autorizados para tomar las decisiones colectivas y bajo qué procedimientos (Bobbio, 1986). Para que ese poder sea legitimado, es necesario garantizar el derecho a votar y que las elecciones sean libres, imparciales (Dahl, 1989), recurrentes y competitivas (Sartori, 1993). Además, la democracia precisa de los derechos de asociación y expresión, de la posibilidad para postularse a cargos públicos y de "instituciones que garanticen que la política pública dependa de los votos y demás formas de expresar las preferencias" (Dahl, 1989, p. 15$)^{11}$.

Quienes son autorizados a través de estos procedimientos y reglas para ejercer un cargo de gobierno o de representación son responsables de adoptar la política que las preferencias ciudadanas delimitan, tanto al emitir su voto como mediante otros instrumentos de retroalimentación (Manin, et al., 1999; Dahl, 1989; Sartori, 1993). La responsabilidad va acompañada de la justificación de cualquier decisión, así sea basada en las preferencias o producto de otra valoración que genere un giro en la política (Stokes, 1999). Además, gobiernos y representantes también están sujetos al control político de la ciudadanía a través de los procesos electorales, de tal manera que las elecciones se convierten en un mecanismo de accountability retrospectivo para premiar o castigar la gestión del partido en el poder (Manin, et al., 1999; Stokes, 2007).

La entrega de beneficios para influir en el voto del elector es la antítesis de las normas y procedimientos recién descritos. En primer lugar, queda condicionada la representación política a intereses particulares. Cuando un político gana a través de la distribución de prebendas, el

${ }^{4}$ Que tiene como objetivo "desmovilizar a los oponentes activos" (Schaffer y Schedler, 2007, p. 5).

${ }^{5}$ Se refiere al ofrecimiento o pago de beneficios particulares a no partidarios o partidarios pasivos para que muestren apoyo político, y no electoral, a un determinado candidato -esto con la intención de persuadir a otros electores a que voten por el candidato (Nichter, 2014).

${ }^{6}$ En esta, partidos y candidatos ofrecen recompensas a no partidarios u opositores para que no asistan a votar (Schaffer, 2002).

${ }^{7}$ El clientelismo sí es un intercambio permanente entre un patrón y un cliente a través de un intermediario, en donde el patrón otorga al cliente prestaciones materiales, bienes y servicios, a cambio de apoyo político-electoral y de fidelidad y solidaridad (Roniger, 1990; Auyero, 2012; González, 2019).

${ }^{8}$ Este hace referencia a la distribución de puestos en la administración pública como recompensa al respaldo electoral (Piattoni, 2001).

${ }^{9}$ Relacionada la distribución de bienes y servicios públicos en el distrito del político, independientemente del apoyo que este haya recibido de los ciudadanos, con la intención de que los beneficiarios respalden al político en la siguiente elección (Stokes et al., 2013)

${ }^{10} \mathrm{En}$ la que el beneficio se entrega selectivamente a un individuo o un pequeño grupo de ciudadanos y, al igual que el pork barrel, no es contingente al apoyo electoral recibido (Nichter, 2014).

${ }^{11}$ Cabe señalar que este apartado no pretende hacer una revisión exhaustiva de las condiciones mínimas para considerar un régimen democrático, sino recuperar algunos de los procedimientos de estos regímenes que se ven directamente afectados por la compra de votos. 
compromiso de impulsar una agenda política a partir de las preferencias ciudadanas no existe, puesto que el triunfo es producto del intercambio y no del respaldo popular. De modo que hay pocos incentivos para formular propuestas con base en un programa o ideología. En cambio, la tentación y el compromiso por favorecer a determinados grupos, dentro de los que se encuentran las fuentes de financiamiento, son muy altos. En ese sentido, la compra de voto envía un mensaje erróneo a quien accede por esta vía al poder y produce una representación sesgada (Schaffer, 2007a).

En segundo lugar, con la compra de votos las elecciones dejan de ser, cuando menos, libres y equitativas (Schaffer, 2007a), y el sentido de estas como mecanismo de rendición de cuentas y de incorporación de demandas ciudadanas se pervierte (Stokes, 2007). Por un lado, el principio de equidad se quebranta cuando un partido tiene mayor acceso a recursos económicos, políticos o mediáticos que el resto de los competidores. Si los recursos económicos sirven para comprar votos, la inequidad es aún mayor, ya que el dinero no es declarado ni sujeto a ningún control de fiscalización, pues la actividad a realizar es ilícita. El dinero no solo genera una competencia desigual, sino que, en este caso, está por fuera de los márgenes legales y tiene como finalidad la manipulación, y no persuasión del elector.

Por otro lado, los ciudadanos que venden su voto pierden la oportunidad de juzgar a los candidatos y partidos por su gestión al frente del gobierno, refrendándolos o retirándoles el apoyo, o de elegir una oferta política a partir de otros criterios como sus propuestas de campaña (Stokes, 2007). Además de afectar la accountability vertical, la compra de votos limita la posibilidad de incorporar las demandas a la agenda política de una parte de la población. Al reducir las elecciones a una transacción, son reemplazados el debate y la deliberación sobre las necesidades, los deseos y aquellos asuntos de interés público que competen a toda una comunidad. Este círculo vicioso termina por excluir políticamente a la población más vulnerable, siendo esta la principal fuente de votos (Stokes, 2007).
Como bien han documentado diversos autores, las personas de escasos recursos son las más vulnerables y propensas a formar parte del intercambio (Brusco et al., 2004; Stokes, 2007). En sociedades muy desiguales y de difícil acceso a bienes y servicios es más probable que los pobres acepten la prebenda que representa una ganancia inmediata y no esperar a ver el resultado de una política pública. Además, está el valor de la utilidad marginal, pues el pago representa una ganancia mayor para una persona de bajos ingresos que para una de ingresos medios o altos (Stokes, 2007).

A las implicaciones anteriores se suma que la compra del voto, como actividad delictiva que es, tiene consecuencias jurídicas. En Colombia constituye uno de los 16 delitos electorales sancionados por el Código Penal; se precisa como "Corrupción al sufragante" dentro del artículo 390, el cual establece lo siguiente:

El que celebre contrato, condicione su perfección o prórroga, prometa, pague o entregue dinero, dádiva $\mathrm{u}$ ofrezca beneficio particular o en favor de un tercero a un ciudadano o a un extranjero habilitado por la ley con el propósito de sufragar por un determinado candidato, partido o corriente política, o para que lo haga en blanco o se abstenga de hacerlo, incurrirá en prisión de cuatro (4) a ocho (8) años y multa de doscientos (200) a mil (1.000) salarios mínimos legales mensuales vigentes. ${ }^{12}$

La pena se aumenta de una tercera parte a la mitad cuando la conducta es realizada por un servidor público, y de la mitad al doble cuando en la promesa, pago o entrega de dinero, beneficios o dádivas medien recursos públicos. Las multas y penas en Colombia son de las más altas en comparación con el promedio latinoamericano. Pero este caso tiene una particularidad adicional; considera también como sujeto de delito a quien obtenga o acepte alguno de los beneficios particulares ofrecidos, en este caso el sufragante. Aún más, la norma establece la misma sanción al comprador que al vendedor del voto. ${ }^{13}$ De modo que la ley no considera la desproporcionalidad que existe entre los individuos sujetos de castigo ni las dificultades que plantea su ejecución -sobre todo

${ }^{12}$ Este agravante se adicionó con la Ley 1864 de 2017 (Oficina de Naciones Unidas contra la Droga y el Delito y Fiscalía General de la Nación, 2018). 
en un país tan desigual y con graves problemas de impartición de justicia-. ${ }^{14}$

Considerando que el dinero para financiar esta actividad ilícita debe permanecer en secreto (Serra, 2016), quien compra votos generalmente incurre en otros delitos electorales. El primero es el financiamiento con fuentes prohibidas, puesto que el dinero que ingresa para cubrir los costes de la red no se declara -y en muchos casos es de procedencia ilegal- (art. 396 A Código Penal). Las fuentes de ese dinero son muy variadas, destacando el desvío de recursos públicos, los aportes de particulares -en especial de grandes contribuyentes- y de la delincuencia organizada. $\mathrm{El}$ segundo delito es la superación de topes de campaña, lo que muy probablemente ocurre al utilizar dinero no declarado (art. 396 B Código Penal).

\section{Estrategia de investigación}

El caso seleccionado, la red de compra de votos encabezada por la excongresista y exsenadora Aída Merlano, es representativo de una práctica común en Colombia. Según los últimos informes de la Misión de Observación Electoral de los procesos generales de 2018 y locales de 2019, $379^{15}$ y 461 municipios, respectivamente, se encontraban en condición de riesgo de fraude electoral. Entre las variables de análisis de riesgo está la compra de voto, y los municipios distribuidos a lo largo de todo el territorio nacional (MOE, 2018; 2019). En ese sentido, se trata de un caso típico, lo que permite conocer las características y consecuencias de un fenómeno que está presente en otras partes del país (Yin, 2003).

La información que sustenta gran parte de la descripción del caso proviene de entrevistas tipo conversación guiada (Hancock y Algozzine, 2006) realizadas a miembros de diferentes corrientes partidistas que conocen del funcionamiento de la compra de votos en el municipio de Barranquilla. A los entrevistados se les contactó en distintas ocasiones; una primera ola sirvió para tener un panorama amplio sobre la compra de votos (organización, equipo de trabajo y logística), y en posteriores conversaciones se profundizó sobre temas específicos (funciones de algunos de los integrantes, fuentes de financiamiento, entre otros aspectos). Las entrevistas se celebraron entre noviembre de 2019 y marzo de 2020. Uno de los informantes colaboró en la campaña electoral de Aída Merlano en 2018. Se mantiene el anonimato de todos los entrevistados.

\section{Compra del voto en Colombia}

\section{Elecciones generales de 2018: Contexto politico-institucional}

En las elecciones generales de 2018 se renovó el Congreso Nacional y la Presidencia de la República. El 11 de marzo los colombianos votaron para elegir a los integrantes del Senado y de la Cámara de Representantes, y el 27 de mayo tuvo lugar la elección para presidente y vicepresidente. Los principales candidatos presidenciales fueron Iván Duque (Partido Centro Democrático, 34.19\%), Gustavo Petro (Coalición Petro presidente, 25.08\%), Sergio Fajardo (Coalición Colombia, 23.73\%), Germán Vargas Lleras (Coalición Mejor Vargas Lleras ante todo Colombia, 7.28\%) y Humberto de la Calle (Coalición Partido Liberal-Alianza Social Independiente, 2.06\%). En la segunda vuelta, celebrada el 17 de junio, Iván Duque ganó a Gustavo Petro con el 53.98\% de los votos (Registraduría Nacional, 2018).

Estas elecciones generales resultaron históricas, ya que por primera vez participó el partido que surgió de las FARC-EP, ahora llamado Fuerza Alternativa Revolucionaria del Común (FARC). Como parte del acuerdo, a las FARC le fueron otorgados curules especiales. Además, por primera vez un candidato de izquierda con exmilitancia guerrillera, Gustavo Petro, disputó la segunda vuelta obteniendo ocho millones de electores, en un país gobernado tradicionalmente por la derecha. De igual modo, fueron las primeras elecciones luego de la reforma política de 2017 por la que se aprobó el Estatuto de la Oposición, que permite a los candidatos a presidente y vicepresidente de la República que quedaron en segundo puesto obtener una curul en el Senado y una en la Cámara de

\footnotetext{
${ }^{14}$ Así, por un lado, la norma equipara a quien acepta recibir o recibe 15 USD por su voto con quien posee recursos para comprar miles de sufragios, ignorando la desigualdad de condiciones entre involucrados y la corresponsabilidad que tiene el Estado en la generación o sostenimiento de dicha desigualdad. Por otro lado, en la práctica, la norma choca con la realidad, pues el aparato de justicia es incapaz de aprehender, enjuiciar y encarcelar a los miles de electores que elección tras elección ofrecen su voto al mejor postor.

${ }^{15} \mathrm{La}$ cifra hace referencia a los factores indicativos de fraude electoral a Senado de la República (MOE, 2018).
} 
Representantes, respectivamente (Artículo 24, Ley 3 de 2017). Por esta vía ingresaron Gustavo Petro al Senado y su fórmula para vicepresidencia a la Cámara de Representantes.

En ese contexto político-institucional, Aída Merlano se presentó al Senado por el Partido Conservador Colombiano (PCC), ganó un escaño con 73,250 votos, se ubicó como la décima candidata con el mayor número de sufragios de su agrupación política (Registraduría Nacional, 2018). Poco más del $80 \%$ de los votos de Merlano provinieron de la región Caribe, principalmente de los Departamentos del Atlántico (37.12\%), Bolívar (33.98\%), Magdalena (7\%) y Cesar (2\%). La ciudad que más aportó para su victoria fue Barranquilla, sede de su casa de campaña política, en donde recibió 26,762 votos (32\% del total) (Gobierno de Colombia, 2018).

El proceso en contra de Merlano se inició en marzo de 2018 a través de una denuncia que alertó a la Policía Nacional de Barranquilla sobre una posible actividad delictiva en la sede política de la candidata. Dos días después de la denuncia, la sede de su campaña -denominada "casa blanca" o "comando"- fue allanada por orden de la Fiscalía 17 Seccional de la Unidad de Administración Pública de Barranquilla. En el lugar se encontraron 18 computadores que contenían información de electores, letras de cambio, recibos de caja, DVD de las cámaras de seguridad, seis carpetas con listados de electores, certificados electorales, 261 millones de pesos en efectivo $\left(91,500\right.$ USD) ${ }^{16}$ y cuatro armas de distinto calibre.

En el mes de abril, a Merlano se le dictó detención preventiva sin beneficio de excarcelación por posible coautoría de los delitos de corrupción al sufragante agravado, ocultamiento, retención y posesión ilícita de cédula, fabricación, tráfico o porte ilegal de armas de fuego, accesorios, partes o municiones. Por tal motivo, la excongresista fue acusada por la Sala de Instrucción de Casación Penal. El juicio concluyó con una condena de 15 años de prisión para la imputada por los delitos de concierto para delinquir agravado, previsto en el artículo 340 inciso 3 del Código Penal, coautora por los punibles de corrupción al sufragante, previsto en el artículo 390, y tenencia de armas de fuego y municiones del artículo 365.

Según la sentencia, se calcula que Merlano orquestó y dirigió una organización criminal electoral-conformada por empresarios, particulares y políticos- que tenía como finalidad la compra masiva de votos para perpetuar su hegemonía política en el poder (Radicación 52418. CSJ, 2019) ${ }^{17}$. Tras ser condenada y estar cumpliendo sentencia en la cárcel del Buen Pastor, en Bogotá, Aída Merlano acudió escoltada el 2 de octubre de 2019 a una cita odontológica en el Centro Médico de la Sabana, al norte de Bogotá. De este lugar escapó por una ventaja colgándose de una soga y no se supo más de ella hasta que reapareció en Venezuela, al ser detenida por las autoridades de ese país el 28 de enero de 2020. Hasta el momento en que se redacta este artículo (noviembre de 2020), Merlano permanece detenida en Venezuela.

\section{Organización e integrantes de la red de compra de votos}

La red de compra de votos funcionó como una empresa compuesta por empleados, políticos locales y regionales, intermediarios y empresarios. Todos los participantes tuvieron una responsabilidad específica al interior de la organización a fin de alcanzar el objetivo principal: conseguir el mayor número de votos para los candidatos que formaban parte del entramado. Al frente de la maquinaria se encontraba Aída Merlano quien, según información del caso, ideaba la estrategia que sería ejecutada y coordinaba reuniones con su círculo más cercano y con empresarios y políticos de la región (Radicación 52418. CSJ 2019).

Con el fin de facilitar la comprensión analítica de la estructura y funcionamiento de la red de compra de voto, se optó por dividir en dos grandes áreas de actividades que desempeñaron los involucrados. Una que podría denominarse fiscal-administrativa y la otra político-operativa. La primera se encargaba de gestionar y ejecutar los recursos con los que operaba la red. Dichos recursos servían principalmente para pagar nómina, servicios y mantenimiento de bienes inmuebles. Dentro de la nómina se encontraba el personal

${ }^{16}$ Todas las conversiones se hicieron con base en el tipo de cambio promedio del mes de marzo de 2018 (Grupo Aval 2020).

${ }^{17}$ Este caso adquirió notoriedad nacional tanto por la magnitud de la red de compra de votos, como por la presunta participación de políticos y empresarios pertenecientes a dos de las casas políticas más importantes de la región Caribe. Se trata de integrantes de la familia Gerlein y la familia Char. De la primera se encuentra implicado el contratista Julio Gerlein, hermano del exsenador Roberto Gerlein, mientras que de la segunda es el senador Arturo Char, hijo del exsenador Fuad Char y hermano del exalcalde de Barranquilla Arturo Char (El Tiempo, 2019). 
directamente vinculado a la sede de campaña. Otra parte del recurso servía para el "sostenimiento" de las casas de apoyo y de los líderes, la adquisición de material de distinta índole -como papelería y equipo de cómputo- y los traslados de personal y su alimentación.

$\mathrm{El}$ área fiscal-administrativa llevaba el listado de los integrantes de la red -como líderes y coordinadores- y de los ciudadanos dispuestos a vender su voto. El personal afiliado al área trabajaba directamente en el comando, lugar que fungía como centro de operaciones ubicado en la casa de campaña. Allí se encontraban tesoreros, secretarias, pagadores, revisores y personal de seguridad. Al lugar también acudían el gerente de campaña, políticos afines al movimiento, candidatos a algún cargo en ese proceso electoral, empresarios, operadores políticos y líderes y coordinadores, mas no así los electores.

Los intermediarios como líderes y coordinadores solo podían ingresar al comando portando un carné que se les proporcionó para identificarlos. El carné contenía el nombre, especificaba la actividad en la parte inferior con la insignia "Líder de Aída M" junto con el logotipo de su campaña, partido y número de la papeleta electoral (Noticias Caracol, 2018). Esta identificación exclusiva fue una de las medidas de seguridad que muestra que el ingreso a la "casa blanca" estaba restringido a cierto personal. Una medida para evitar reunir a los electores en el recinto y llamar la atención de las autoridades, pues la compra de votos, como actividad ilegal que es, requiere de gran discreción (Wang y Kurzman, 2007).

Por su parte, el área político-operativa, organizada jerárquicamente y con funciones claramente asignadas, estuvo a cargo de la ejecución de la estrategia electoral. Dentro de las responsabilidades de esta área se encontraban organizar y supervisar las casas de apoyo, buscar y movilizar electores, instruirlos a través de la "pedagogía electoral" y verificar el conteo de votos. La cúspide de esta estructura estaba reservada para las personas de mayor influencia política y cercanía a la congresista. En tal condición se encontraban concejales, diputados locales y candidatos a puestos de representación. Este entramado de operadores aportó votos y capital político.

Algunos de los operadores identificados en el proceso judicial en contra de Merlano fueron la aspirante a la Cámara de Representantes por el Partido Cambio Radical, Lilibeth Llinás ${ }^{18}$, la diputada por el Atlántico, Margarita Ballén, y los concejales Aissar Castro Bravo, Vicente Carlos Támara y Juan Carlos Zamora. Según uno de los testigos que declaró en el juicio, los políticos trabajaban conjuntamente y con el propósito de ganar las elecciones bajo el lema "tú me ayudas, yo te ayudo, tú me apoyas, yo te apoyo" -a pesar de pertenecer a diferentes agrupaciones políticas(Radicación 52418. CSJ, 2019: 15).

Por debajo de los operadores políticos se encontraban coordinadores y líderes. Los primeros, como su nombre lo indica, tenían bajo su responsabilidad la coordinación de los líderes mediante la asignación de labores específicas. En tanto que los líderes, como eslabón más cercano al elector, se enfocaban en aportar los electores que venderían su voto. Pero para llevar a cabo tal función los líderes desempeñaban otras actividades, dentro de las que destaca la instrucción a los ciudadanos sobre cómo y por quién votar el día de las elecciones. A esto se le denomina "pedagogía electoral"19. Con ello intentaban asegurar que el elector fuera capaz de cumplir con la parte que le correspondía dentro del acuerdo ilegal, reduciendo así el margen de pérdida por error o desconocimiento. Otra función, tanto de coordinadores como de líderes, tenía que ver con la movilización electoral. Estos intermediarios eran los responsables de procurar que el ciudadano acudiera a las urnas el día de las elecciones.

La capacidad organizativa de Merlano junto con el capital electoral que heredó del exsenador Roberto Gerlein ${ }^{20}$ y sus acuerdos politicos -propios de la coyuntura del proceso electoral de 2018-, fueron elementales para ampliar su radio de influencia. Esto le permitió contar con líderes y comprar votos no solo en Barranquilla y municipios aledaños del

\footnotetext{
${ }^{18}$ Lillibeth Llinás fue la fórmula que acompañaría a Merlano en la cámara baja. Según información difundida en el juicio a Merlano y publicada en medios de comunicación, la candidatura de Llinás fue parte del acuerdo entre la familia Gerlein y la familia Char (El Espectador, 2020).

${ }^{19}$ La "pedagogía electoral" no es una función exclusiva de las redes de compra de voto, sino que ha sido una actividad llevada a cabo desde hace mucho tiempo en las casas de apoyo (Informantes 1 y 3 ). Esto debido a la falta de conocimiento de algunos ciudadanos sobre cómo ejercer su derecho. El problema con esta práctica es el "mal uso que se le ha dado", puesto que existe una delgada línea entre enseñar a ejercer el voto e inducir a votar por un problema con esta práctica es el "mal uso que se le ha dado",

${ }^{20}$ Roberto Gerlein fue senador de la República durante cinco décadas. Roberto, junto con sus hermanos Julio, empresario que ha recibido múltiples contratos de obra pública, y Jorge, quien fue suplente de Roberto (1990-1991) y Representante a la Cámara (1992-2006), construyeron una "empresa electoral" a la que se atribuye la creación del TLC (Tejas, Ladrillos y Cemento), una estrategia de intercambio de materiales de construcción por votos (Pérez, 2018).
} 
departamento del Atlántico, sino también en los departamentos de Magdalena, Bolivar y el Cesar. Se estima que entre líderes y coordinadores eran alrededor de 1000 personas las encargadas de comprar los votos (Radicación 52418. CSJ, 2019). Para el trabajo de todos estos fueron destinados recursos del rubro denominado "sostenimiento".

Además de la red de intermediarios, dentro del personal directamente vinculado al comando central del área político-operativa, merecen una consideración especial los llamados "didactas" y "punteadores". Según los informantes, los primeros son personas ajenas a la red contratadas ocasionalmente antes de la elección, por lo que no tienen una relación directa ni conocen acerca del manejo de los recursos, las decisiones o la forma en que operan las candidaturas. Su función es auxiliar a los líderes en enseñar a la población a marcar la boleta electoral. A su vez, acompañan a estos últimos en los barrios y reuniones. El día de la elección los didactas se encargan de realizar una última prueba a los electores en las casas de apoyo. En tanto que la labor de los punteadores es de verificación del voto. Estos se presentaban con las listas de los electores comprometidos y verificaban su asistencia a las urnas (Informantes 1 y 2).

\section{Logistica, pagos, recursos y target}

El equipo que encabezó Merlano comenzó su ejecución casi un año antes de las elecciones de marzo de 2018. Lo primero fue reorganizar a líderes con los que había trabajado en elecciones previas ${ }^{21}$. Los "mochileros y taquilleros -conocidos como líderes en expansión- tienen negociada la venta desde un año antes de la elección" (Informante 1). También inició la búsqueda de nuevos líderes interesados en apoyar la candidatura para adherirlos a la red.

A la par de la negociación con líderes y coordinadores comienzan los procesos para "planillar" y "zonificar". A través del primero "se recopila, relaciona y registra la información” del elector, la cual "se plasma inicialmente en unos formatos (planillas) que incluyen, entre otros aspectos, [...] nombre completo del votante, número de cédula, lugar de votación y residencia y nombre del intermediario responsable.” (González, et. al., 2019, p. 69). Mientras que la zonificación es la inscripción del documento de identidad en una localidad diferente a la de residencia o nacimiento por medios indebidos y con el propósito de obtener ventaja en una elección popular. Esta se conoce también como "trasiego" o "trashumancia" de electores, y está consagrada como delito de "Fraude a inscripción de cédulas” en el artículo 389 del Código Penal.

La zonificación como instrumento de movilización electoral adopta sentido político, sin obviar su carácter ilegal, cuando partidos y candidatos buscan obtener mayor apoyo en una determinada localidad. Pero ¿qué sentido tendría mover al electorado de puesto de votación si para elegir senadores -como en el caso de Aída Merlanose vota en una única circunscripción nacional? La razón es que sirve como mecanismo de control, pues el elector es trasladado a la zona de influencia del intermediario político en donde este tiene desplegada una mayor capacidad operativa y de gestión (Informante 3).

Una vez confirmada la planilla de electores, era entregado un adelanto por cada voto comprometido, el cual equivalía a 15,000 COP (US\$5.3). Por zonificación se otorgaban 20,000 COP (US\$7.0), de los cuales 10,000 COP eran para el líder y 10,000 COP para el elector (Informante 1). En el comando permanecía la información de líderes y de los ciudadanos dispuestos a vender su voto. Los datos personales de los vendedores número de cédula, lugar de residencia, teléfono y huella dactilar-, fueron capturados por el equipo administrativo. Mediante un software diseñado ad hoc, esos datos se cotejaron con información de la Registraduría Nacional para asegurar que el elector estuviera empadronado en el lugar convenido.

Este proceso tenía dos finalidades más; primero, guardar información del elector asociada a su líder para realizar los pagos; y segundo, compartir las listas con otros candidatos para verificar que el líder no estuviera vendiendo sus votos a más de un candidato o partido político. En caso de que resultara "positivo", es decir, que se constatara que el líder ofreció la lista a más de un candidato, enseguida se procedía a anularlo de la red (Informante 1). Al no

${ }^{21}$ Por ejemplo, cuando fue elegida representante en 2014. De hecho, el juicio en contra de Merlano evidenció que la red de compra de voto se configuró en elecciones anteriores en las que la excongresista participó como candidata y/o apoyó a otros candidatos tanto al Concejo de Barranquilla como al Congreso y al Senado. 
poder acudir a instancias oficiales para denunciar un fraude, desde la dirección de la red se diseñó una estrategia de intercambio de información entre políticos de diferentes partidos para evitar la estafa de los líderes. Este tipo de acciones evidencia el nivel de sofisticación de las redes y la amplitud del fenómeno de la compra de voto en la región Caribe. Pero la tolerancia hacia estas prácticas también abre la posibilidad de una complicidad entre la política y las instituciones encargadas de perseguir y castigar esos delitos (Informante 3).

El día de las elecciones, en las casas de apoyo se encontraban los didactas cuya finalidad, como se mencionó anteriormente, era verificar si el elector sabía por quién debía ejercer su voto (Informante 2). Realizada la prueba, se entregaba un papel al elector -conocido por la Fiscalía como sticker-, que podía ser rosa o gris, con la frase "GRACIAS POR TU APOYO" dentro de un corazón y un código QR en la esquina inferior izquierda. El llamado "papel rosado" significaba que el elector sabía por quién votar, el "papel gris" significaba lo contrario.

Tras su paso por la casa de apoyo, y con el papel correspondiente, el elector podía acudir al puesto de votación. Efectuado el sufragio, sticker y certificado electoral eran entregados al líder político. Con estos el líder acudiría al comando para cobrar los restantes 35,000 COP (\$12.3 USD) por el voto emitido. $\mathrm{El}$ código $\mathrm{QR}$ de los stickers estaba asociado al líder, de modo que al ser leído por el sistema se registraba la cantidad de votos que había conseguido. Esto facilitaba el conteo para efectuar el pago. Además, el código garantizaba la originalidad del papel para evitar falsificaciones (Informante 1).

Como si se tratase de una empresa establecida en un mercado legal que recompensa a sus empleados por su desempeño, en la red de compra masiva de votos se premiaba a los líderes destacados. El líder que lograra el 70\% de los votos comprometidos recibiría una bonificación de 15,000 COP (5.3 USD) por cada voto adicional. El porcentaje para alcanzar la bonificación equivalía al estimado de pérdida, pues por cada 100 votos comprados se perderían 70 (Informante 1). De modo que dos de cada tres votos podían perderse por incumplimiento del líder, por error, inasistencia o giro del elector al sufragar por otro candidato distinto al que le vendió su voto.

El sostenimiento de las casas de apoyo, líderes y coordinadores, pagos de servicios y nómina, así como las bonificaciones necesitan sumas importantes de recursos económicos. La trama identificada en Barranquilla confirmó e hizo de dominio público la financiación procedente de grandes empresarios y contratistas. El principal implicado, actualmente sujeto a indagatoria, es el empresario Julio Gerlein. En distintas ocasiones Aída Merlano ha acusado a Julio Gerlein de haber financiado la campaña y de ser quien "manejaba la sede" (Pulzo, 2020). ${ }^{22}$ En todo este modelo, la candidata fue la intermediaria más importante de una amplia red que tuvo en la cima al empresario.

\section{Implicaciones politicas y sociales de la compra de voto en Colombia}

Como se mencionó al inicio del estudio, la compra de voto es una práctica que afecta la representación política y las elecciones, y que tiende a mantener las desigualdades sociales. El primer elemento para destacar es que el coste de una red tan compleja como la descrita en el apartado anterior termina siendo asumido indirectamente por la población. Siguiendo el testimonio del Informante 1, por cada 100 votos comprados el grupo encabezado por Merlano estimaba conseguir solo 30 sufragios, lo que representaba una pérdida del $70 \%$ de lo erogado. En otras palabras, cada voto asegurado tuvo un costo de $166,666 \mathrm{COP}^{23}$. A ese rubro habrá que añadir los recursos necesarios para el sostenimiento de personal y equipo técnico, renta de inmuebles y gastos para transporte y alimentación.

Según información que arrojó el juicio de Merlano, durante la campaña electoral el grupo invirtió cerca de 6.000 millones $\mathrm{COP}^{24}(2,1$ millones USD) en la compra de más de 300.000 votos (Radicación 52418. CSJ, 2019). Si bien no existe certeza de cuánto se gastó en la trama, al menos se

\footnotetext{
${ }^{22}$ En uno de los videos de la sede de campaña, a Merlano se le ve molesta luego de una reunión con Gerlein. En el video se escucha que se queja por recibir menos dinero del empresario del necesario: "a lo bien ya el debate me lo bajó a 1.300 según él; o sea no pagamos casas de apoyo, no pagamos votos, no pagamos; (...) tú crees que yo voy a dejar de pagarle a los líderes (...) pa' cerrar el debate necesito 2300 (...), nosotros nos terminamos gastando la mitad, es correcto. Pero por mucho que quiera ahorrar, esa vaina no baja de 1.500 millones. No baja" (Semana, 2019).

${ }^{23} \mathrm{La}$ falta de certeza sobre la decisión que tomará el elector que vendió su voto, a la que hizo referencia el informante, sustenta la afirmación de Stokes (2007), en el sentido en que los partidos no compran votos sino "votos esperados" (p. 86).

${ }^{24}$ Esta estimación supera por mucho el tope máximo de gasto permitido para la campaña que era de 884 millones.
} 
conoce la procedencia de gran parte de los recursos: las aportaciones del empresario Julio Gerlein, cuya inversión, de acuerdo con el juicio y el Informante 1, vería recuperada a partir de la obtención de contratos del Estado. Esta dinámica tiene efectos perjudiciales para el grueso de la población. Los empresarios -y otros grandes capitales- aportan dinero para que los candidatos compren votos porque persiguen un interés específico. Los aportes generan ataduras y compromisos a los políticos ex ante, esto es, previa victoria y posicionamiento en el cargo. Una vez en funciones, los políticos deben pagar "el favor", para lo cual disponen de varias medidas: cabildeo a favor de los grupos de financiamiento; compensaciones fiscales; asignación de licitaciones para llevar a cabo obra pública; modificaciones al presupuesto, entre otros.

Las acusaciones que pesan sobre el empresario barranquillero Julio Gerlein evidencian que la compra masiva de votos ha formado parte de una práctica sistemática de un clan político para obtener recursos del Estado y aumentar su influencia y capital económico. Julio Gerlein tiene un largo historial financiando campañas electorales, y durante más de 30 años ha recibido contratos de obra pública. Una de sus empresas, Valores y Contratos (Valorcon), fundada en 1992, ha participado en más de 100 proyectos de infraestructura -vial, de vivienda, deportiva e industrial-, tanto a nivel local como nacional, convirtiéndose en uno de los contratistas más importantes del país (La Silla Vacía, 2016). De modo que la compra de votos, en este y otros casos, ha sido financiada con dinero público otorgado al contratista por medio de licitaciones hechas a modo. Esos recursos, en un sistema donde prime el estado de derecho, deben asignarse de forma transparente, mediante licitación abierta y competitiva, y no con favoritismos.

Si la política pública queda condicionada de antemano, hay un claro sesgo de representación política a favor de unos cuantos grupos e intereses particulares y en detrimento del grueso de la población. Lo mismo sucede en términos de responsabilidad: el político es responsable (accountable) ante el patrón que financió la campaña y la trama ilegal, en este caso un contratista, y no frente al electorado. Es en ese sentido que se promueven incentivos erróneos en quienes ganan un cargo de elección popular comprando votos.
Junto a la falta de responsabilidad de los políticos, el caso pone de manifiesto cómo quedan socavados derechos políticos como el libre ejercicio del sufragio y la igualdad de expresar preferencias sobre asuntos de interés público. Los ciudadanos que decidieron votar por Merlano a cambio de la prebenda recibida -concentrados principalmente en la Costa caribe colombiana-, perdieron la oportunidad de juzgar a los candidatos por sus acciones previas o por sus propuestas de campaña. A la par de hacer a un lado la oportunidad de evaluar retrospectiva o prospectivamente, renunciaron a su derecho a expresar su inconformidad y desacuerdo con los candidatos si es que ninguna opción política resultaba de su agrado.

Por último, la venta del voto evita que las demandas ciudadanas sean incorporadas en la agenda política, en especial de los más necesitados, quienes son el principal objetivo de los intermediarios. A partir de las implicaciones anteriores surge una evidente paradoja: la compra de votos favorece a quienes acceden al poder por esta vía y perjudica a los estratos más bajos, pero son estos últimos la principal fuente de sufragios. Partidos y candidatos continúan tomando ventaja de los pobres y de su falta de autonomía (O’Donnell, 1996).

\section{Reflexiones finales}

Este estudio tuvo como objetivos describir cómo opera una red de compra de votos y reflexionar sobre las implicaciones de dicha estrategia de movilización. El caso analizado es representativo de una práctica extendida en mayor o menor intensidad por todo el territorio colombiano. La red que encabezó Aída Merlano desde la ciudad de Barranquilla funcionó con un alto grado de sofisticación, destacando la división de personal de acuerdo con la actividad a desarrollar, el equipo tecnológico que facilitaba el manejo de información y las fuentes de financiamiento para cubrir gastos y compromisos adquiridos. Todo este capital fue invertido con la finalidad de que los candidatos involucrados ganaran la elección, pero también con el objetivo de que un grupo económico continuara apropiándose de recursos del Estado.

Con relación a los efectos, cabe concluir que la compra de votos es una estrategia de manipulación política sumamente dañina porque, además de afectar instituciones democráticas, contribuye a empeorar la 
calidad de la ciudadanía. Estrategias de movilización política como el clientelismo pueden reforzar redes sociales de cooperación para exigir mejores servicios o facilitar la participación (Cruz, 2019), sobre todo en escenarios caracterizados por grandes desigualdades sociales y en donde la presencia del Estado es deficiente (Auyero, 2012). Sin embargo, la compra de voto desincentiva la cooperación y puede estar asociada a la disminución de inversión en la prestación de servicios públicos (Khemani, 2005).

Finalmente, casos como el que aquí se analizó permiten abrir nuevas líneas de investigación. Quedan interrogantes por resolver como cuán efectiva es la compra de voto como estrategia de manipulación y movilización o por qué persiste. Sobre este particular, la literatura argumenta que la estrategia es efectiva cuando los partidos tienen la capacidad de monitorear al ciudadano (Brusco et al., 2004). Según se pudo documentar en este trabajo, la red de coordinadores y líderes junto a los didactas y punteadores sirvió al grupo de Merlano no solo para acompañar y enseñar a los electores, sino para monitorear su comportamiento. Pero este tipo de mecanismos de control y vigilancia solo son efectivos en escenarios de alta corrupción y debilidad institucional. Por ello es necesario enfatizar en la necesidad de fortalecer las instituciones.

Una última línea de investigación que tampoco ha recibido la atención necesaria es la coacción o constreñimiento al sufragante. Es decir, cuando se presiona o amenaza por cualquier medio a una persona para que emita un voto por un candidato o partido específico. En el juicio en contra de Merlano, uno de los testigos afirmó que a través de presiones algunos partidos en la Costa obtienen votos de servidores públicos y empleados del sector privado. Bajo esta modalidad, se amenaza con despidos a funcionarios y trabajadores si no llevan a las urnas a un número determinado de electores. Esta modalidad no resultaría ajena en una región donde los políticos están vinculados al mundo empresarial. Por tanto, queda pendiente para ser explorada en futuras investigaciones.

\section{Bibliografia}

Auyero, J. (2012). La política de los pobres. Las prácticas clientelares del peronismo. Buenos Aires: Manantial.

Bobbio, N. (1986). El futuro de la democracia. México: FCE. https://doi.org/10.22201/fcpys.24484903e.1986.2.60044

Brusco, V., Nazareno, M., \& Stokes S. (2004). Vote Buying in Argentina. Latin American Research Review, 39(2), 66-88. https://doi.org/10.1353/lar.2004.0022
Calvo, E. y Murillo, M. (2004). Who Delivers? Partisan Clients in the Argentine Electoral Market. American Journal of Political Science, 48(4), 742-757. https:// doi.org/10.1111/j.0092-5853.2004.00099.x

Cruz, C. (2019). Social Networks and the Targeting of Vote Buying. Comparative Political Studies, 52(3), 382-

411. https://doi.org/10.1177/0010414018784062

Corte Suprema de Justicia (2019). Radicación 52.418, Sala Especial de Primera Instancia, Colombia.

Cox, G., y McCubbins, M. (1986). Electoral Politics as a Redistributive Game. The Journal of Politics, 48(2), 370-389. https://doi.org/10.2307/2131098

Dahl, R. (1989). La poliarquía. Madrid: Tecnos.

Díaz, E. (1986). El clientelismo en Colombia. Un estudio exploratorio. Bogotá: El Áncora.

Díaz-Cayeros, A., Estévez, F., \& Magaloni, B. (2016). The political Logic of Poverty Relief: Electoral Strategies and Social Policy in Mexico. Cambridge: Cambridge University Press. https:// doi.org/10.1017/CBO9781316492710

El Tiempo (2019, octubre 1). Los poderosos de la Costa a quienes toca fallo contra Aída Merlano. Recuperado de https://www.eltiempo.com/justicia/ cortes/los-detalles-de-la-condena-contra-senadora-aidamerlano-por-corrupcion-electoral-412960

Fergusson, L., Molina, C., \& Riaño, J. (2017). I sell my vote, and so what? A new database and evidence from Colombia. Documentos de Trabajo, 20, CEDE. https://doi.org/10.2139/ssrn.2935385

Gobierno de Colombia (2018). Datos abiertos. Recuperado de https://www.datos.gov.co/Resultados-Electorales/ RESULTADOS-ELECTORALES-2018-SENADO-DE-LAREPUBLICA/949k-z6ky

González, L. (2019). Introducción: claves para entender el clientelismo político. En González, L. (Dir.), Clientelismo, patronazgo y corrupción en Colombia y México (pp. 1-21). Bogotá: Universidad del Norte. https://doi.org/10.2307/j. ctvh9w17d.4

González, L., Guzmán, C. y Tuirán, A. (2019). Clientelismo de mediación en Barranquilla. En González, L. (Dir.), Clientelismo, patronazgo y corrupción en Colombia y México (pp. 54-75). Bogotá: Universidad del Norte. https://doi.org/10.2307/j.ctvh9w17d.7

Guillén, F. (2008). El poder político en Colombia. Bogotá: Planeta.

Greene, K. (2016). Why Vote Buying Fails: Campaign Effects and the Elusive Swing Voter. Unpublished Manuscript. University of Texas.

Grupo Aval (2020). Portal Financiero. Recuperado de https:// www.grupoaval.com/wps/portal/grupo-aval/aval/portalfinanciero/monedas/dolar/datos-historicos

Hancock, D., \& Algozzine, B. (2006). Doing Cases Study Research. A Practical Guide for Beginning Researchers. EE.UU.: Columbia University. 
Heckathorn, D. (1997). Respondent-Driven Sampling: A New Approach to the Study of Hidden Populations. Social Problems, 44(2), 174-199. https://doi. org/10.2307/3096941

Hagene, T. (2015). Political Clientelism in Mexico: Bridging the Gap Between Citizens and the State. Latin American Politics and Society, 57(1), 139-162. https://doi.org/10.1111/j.1548-2456.2015.00259.x

Hidalgo, D., \& Nichter, S. (2016). Voter Buying: Shaping the Electorate through Clientelism. American Journal of Political Science, 60(2), 436-455. https:// doi.org/10.1111/ajps.12214

Khemani, S. (2015). Buying votes versus supplying public services: Political incentives to under-invest in pro-poor policies. Journal of Development Economics, 117, 84-93. https://doi.org/10.1016/j. jdeveco.2015.07.002

Kitschelt, H., y Wilkinson, S. (2007). Citizen-politician linkages: an introduction. En Kitschelt, $\mathrm{H}$. y Wilkinson, S. (Eds.) Patrons, Clients, and Policies: Patterns of Democratic Accountability and Political Competition (1-49). Cambridge: Cambridge University Press. https://doi.org/10.1017/ CBO9780511585869.001

El Espectador. 2020. La cuota de la casa Char que quería llegar al congreso con el apoyo de Aída Merlano. February 11. https://www.elespectador.com/noticias/ judicial/la-cuota-de-la-casa-char-que-queria-llegar-alcongreso-con-el-apoyo-de-aida-merlano-articulo-904007/

La Silla Vacía. (2016, agosto 25). Julio Gerlein Echeverría. Recuperado de https://lasillavacia.com/quienesquien/ perfilquien/julio-gerlein-echeverria

Leal, F., \& Dávila, A. (2010). Clientelismo: el sistema político y su expresión regional. Bogotá: Universidad de los Andes.

Lehoucq, F. (2007). When does a market for votes emerge? Historical and theoretical perspectives. En Schaffer, C. (Ed.). Elections for Sale: The Causes and Consequences of Vote Buying (33-45). Boulder: Lynne Rienner.

Manin, B., Przeworski, A., \& Stokes, S. (1999). Introduction. En Przeworski, A., Stokes, S. y Manin, B. (Eds.). Democracy, Accountability, and Representation (1-26). EE.UU.: Cambridge University Press. https://doi.org/10.1017/CBO9781139175104.001

Misión de Observación Electoral (2018). Mapas y factores de riesgo electoral. Elecciones nacionales Colombia 2018. Bogotá: Arte Litográfico.

Misión de Observación Electoral (2019). Mapas y factores de riesgo electoral. Elecciones de autoridades locales Colombia 2019. Bogotá: Arte Litográfico.

Nichter, S. (2008). Vote Buying or Turnout Buying? Machine Politics and the Secret Ballot. The American Political Science Review, 102(1), 19-31. https://doi. org/10.1017/S0003055408080106

Nichter, S. (2014). Conceptualizing vote buying. Electoral
Studies, 35, 315-327. https://doi.org/10.1016/j. electstud.2014.02.008

Noticias Caracol. (2018, abril 24). "Ella daba las instrucciones": el relato del testigo que tiene en apuros a Aída Merlano. Recuperado de https:// noticias.caracoltv.com/colombia-decide-2018/ella-dabalas-instrucciones-el-relato-del-testigo-que-tiene-en-apurosaida-merlano-ie11269

O’Donnell, G. (1996). Another Institutionalization: Latin America and Elsewhere. Working Paper, 222, Kellogg Institute for International Studies.

Ocampo, G. (2014). Poderes regionales, clientelismo y Estado. Etnografía del poder y la política en Córdoba, Colombia. Bogotá: Siglo del hombre editores.

Oficina de Naciones Unidas contra la Droga y el Delito y Fiscalía General de la Nación. 2018. Tipologías de corrupción en Colombia. Corrupción electoral. Recuperado de https:/www.fiscalia.gov.co/colombia/ wp-content/uploads/Tomo-VI.pdf

Pérez, J. (2018, enero 21). Roberto Gerlein, el último senador del siglo XX. La Silla Vacía. Recuperado de https:// lasillavacia.com/silla-caribe/roberto-gerlein-el-ultimosenador-del-siglo-xx-64293

Piattoni, S. (2001). Clientelism in Historical and Comparative Perspective. En Piattoni, S. (Ed.). Clientelism, Interest, and Democratic Representation. The European Experience in Historical and Comparative Perspective (1-30). Nueva York: Cambridge University Press. https://doi.org/10.1017/ CBO9781139175340.002

Pulzo (2020, febrero 16). "A la sede política llevaban tulas con dinero y las entregaban a Julio Gerlein": Merlano. Recuperado de https://www.pulzo.com/ nacion/aida-merlano-acusa-nuevo-julio-gerlein-entrevistacon-vicky-davila-PP846832

Registraduría Nacional (2018). Recuperado de https://www. registraduria.gov.co/

Roniger, L. (1990). Hierarchy and Trust in Modern Mexico and Brazil. New York: Praeger.

Rueda, M. (2017). Small Aggregates, Big Manipulation: Vote Buying Enforcement and Collective Monitoring. American Journal of Political Science, 61(1), 163177. https://doi.org/10.1111/ajps.12260

Sandholt, P. y Justesen, M. (2013). Poverty and Vote Buying: Survey-based evidence from Africa. Electoral Studies, 33, 220-232. https://doi.org/10.1016/j. electstud.2013.07.020

Sartori, G. (1993). ¿Qué es la democracia? México: Alianza Editorial.

Sartori, G. (2002). La Política. Lógica y método en las ciencias sociales. México: FCE.

Schaffer, F. (2002). Might Cleaning up Elections Keep People Away from the Polls? Historical and Comparative Perspectives. International 
Political Science Review, 23(1), 69-84. https://doi. org/10.1177/0192512102023001004

Schaffer, F. (2007a). Why Study Vote Buying? En Schaffer, C. (Ed.). Elections for Sale: The Causes and Consequences of Vote Buying (1-16). Boulder: Lynne Rienner.

Schaffer, F. (2007b). Lessons Learned. En Schaffer, C. (Ed.). Elections for Sale: The Causes and Consequences of Vote Buying (183-200). Boulder: Lynne Rienner.

Schaffer, F., \& Schedler, A. (2007). What is Vote Buying? En Schaffer, C. (Ed.). Elections for Sale: The Causes and Consequences of Vote Buying (17-30). Boulder: Lynne Rienner.

Semana (2019, septiembre 13). Los videos que enredan a Julio Gerlein con pagos para la compra de votos de Merlano. Recuperado de https://www.semana.com/ nacion/articulo/los-videos-que-enredan-a-julio-gerleincon-pagos-para-la-compra-de-votos-de-merlano/632160

Serra, G. (2016). Vote Buying with Illegal Resources: Manifestation of a Weak Rule of Law in Mexico. Journal of Politics in Latin America, 8(1), 129-150. https://doi.org/10.1177/1866802X1600800105

Stokes, S. (1999). What Do Policy Switches Tell Us about Democracy? En Przeworski, A., Stokes, S. y Manin, B. (Eds.). Democracy, Accountability, and Representation (98-130). EE.UU.: Cambridge University Press. https://doi.org/10.1017/ CBO9781139175104.004

Stokes, S. (2005). Perverse Accountability: A Formal Model of Machine Politics with Evidence from Argentina. American Political Science Review, 99(3), 315325. https://doi.org/10.1017/S0003055405051683

Stokes, S. (2007). Is Vote Buying Underdemocratic? En Schaffer, C. (Ed.). Elections for Sale: The Causes and Consequences of Vote Buying (81-99). Boulder: Lynne Rienner.

Stokes, S., Dunning, T., Nazareno, M., \& Brusco, V. (2013). Brokers, Voters, and Clientelism. The Puzzle of Distributive Politics. Cambridge: Cambridge University Press. https://doi.org/10.1017/ CBO9781107324909

Tilly, C. (2007). Democracy. Nueva York: Cambridge University Press. https://doi.org/10.1017/ CBO9780511804922

Vicente, P. (2014). Is Vote Buying Effective? Evidence from a Field Experiment in West Africa. The Economic Journal, 124(574), 356-387. https://doi.org/10.1111/ ecoj. 12086

Wang, C. y Kurzman, C. (2007). The Logistics: How to Buy Votes. En Schaffer, C. (Ed.). Elections for Sale: The Causes and Consequences of Vote Buying (61-78). Boulder: Lynne Rienner.

Yin, R. (2003). Case Study Research. Design and Methods. EE.UU.: Sage Publication.
Zarazaga, R. (2014). Vote-buying and Asymetric Information. Working Paper 398, Kellogg Institute for International Studies. 